\title{
Sobre la medicalización de la infancia socialmente problemática: objetos y trayectorias de la psiquiatría
}

Myriam Mitjavila'

\section{Resumen}

El artículo examina los procesos de medicalización de los comportamientos disruptivos en la infancia desde el punto de vista de su codificación por parte del saber psiquiátrico. Se presentan cuatro fases de los procesos medicalizadores de la infancia considerada socialmente problemática y sus articulaciones con estrategias biopolíticas de gestión de la anormalidad.

Palabras-clave: Medicalización. Biopolítica. Comportamiento infantil disruptivo. Psiquiatría

\section{Introducción}

La proliferación relativamente reciente de diagnósticos y tratamientos farmacológicos destinados a controlar los comportamientos socialmente problemáticos de niñas/os y adolescentes se ha convertido en objeto de análisis en diferentes áreas de la salud y de las ciencias humanas y sociales. Examinar esa cuestión en su historicidad puede contribuir a una mejor comprensión del fenómeno en la contemporaneidad. En este ensayo se pretende indagar la omnipresencia actual del trastorno por déficit de atención e hiperactividad (TDAH) y del trastorno de oposición desafiante (TOD) como dos categorías diagnósticas que, en el ámbito de la psiquiatría infantil,

I Professora Titular do Departamento de Serviço Social da Universidade Federal de Santa Catarina (UFSC). Docente do Programa de Pós-Graduação Interdisciplinar em Ciências Humanas e do Programa de Pós-Graduação em Sociologia Política da UFSC e doutora em Sociologia pela Universidade de São Paulo (USP), Brasil. E-mail: myriammitjavila@gmail.com

\section{$(\mathrm{cc})$ Er}

Direito autoral e licença de uso: Este artigo está licenciado sob uma Licença Creative Commons. Com essa licença você pode compartilhar, adaptar, para qualquer fim, desde que atribua a autoria da obra, forneça um link para a licença, e indicar se foram feitas alterações. 
representarían una inflexión del saber médico en relación a las maneras de diagnosticar y tratar a la población infantil que presenta comportamientos considerados socialmente problemáticos. Ambas categorías comparten algunos atributos, tales como permitir ampliar el abanico de condiciones que serían expresiones de anormalidad y, fundamentalmente, identificar diferentes formas y grados de peligrosidad social entre aquellas/os nińas/ os y adolescentes que son objeto de ese tipo de categorización.El propósito de este artículo es examinar esas construcciones nosológicas como parte de las transformaciones experimentadas por la psiquiatría en el contexto de lo que, en términos hipotéticos, podría ser considerado como una resignificación del papel biopolítico de la infancia en función de un nuevo tipo de racionalidad que organiza las sociedades tardo-modernas. En ese sentido, la perspectiva aquí adoptada es estrictamente sociológica, lo que significa decir que las conceptualizaciones neuropsiquiátricas son tratadas como construcciones que no son reductibles a meros impulsos endógenos del propio saber médico, sino como elementos constitutivos de las estrategias biopolíticas que la sociedad desarrolla en cada circunstancia histórica para administrar asuntos socialmente problemáticos. Por lo tanto, permanecen fuera del foco de este análisis aquellos aspectos relativos a contenidos, métodos, eficacia y validez científico-técnica de conceptos e instrumentos de las miradas e intervenciones psiquiátricas en torno a comportamientos disruptivos en la infancia y en la adolescencia. La posición de Eliot Freidson expresa de manera ejemplar las peculiaridades que separan las miradas sociológicas de otras igualmente posibles:

[...] no intento tratar las "causas" del conjunto de signos verificables y medibles empíricamente que a veces el médico llama enfermedad. Esa es, esencialmente, una cuestión médica. En cambio, intentaré tratar las "causas" que designan un conjunto de atributos, y no otro, como enfermedad, y las "causas" de la experiencia y conducta de gente que fue diagnosticada de un modo particular. Esta es una cuestión genéricamente sociológica. (FREIDSON, 1978, p. 210-211).

Esa demarcación epistemológica que plantea Freidson resulta fundamental para comprender las trayectorias experimentadas por el saber médico y sus profundas conexiones con la realidad social de la cual forma parte. Así, si observamos la trayectoria histórica de la psiquiatría infantil desde sus orígenes como especialidad médica hasta nuestros días, 
encontraremos momentos de inflexión conceptual y su materialización en nuevas categorías nosológicas y estrategias terapéuticas que no surgen como un mero resultado de la dinámica misma del conocimiento psiquiátrico y sí, posiblemente, como respuestas biomédicas a cuestiones que se convirtieron en focos de preocupación a escala societal.

Desde sus orígenes, la psiquiatría ha intervenido en la administración de un amplio repertorio de comportamientos que se caracterizan por representar alguna forma de amenaza para el orden social. El interés de la medicina psiquiátrica en la infancia muestra una trayectoria en la cual sus objetos de estudio e intervención profesional experimentaron diversas transformaciones asociadas con contextos sociohistóricos en los cuales el conocimiento médico se reveló como un producto y, al mismo tiempo, como una pieza esencial de las configuraciones de poder en diferentes áreas de la vida social.

En ese sentido, podrían ser identificadas, al menos hipotéticamente cuatro grandes fases o modalidades de problematización de la infancia anormal en los discursos de la medicina psiquiátrica, cada una de ellas caracterizada por privilegiar determinados atributos y comportamientos de niñas/os y adolescentes o, como también será destacado más adelante, por capturar bajo nuevos códigos desviaciones comportamentales ya problematizadas desde el punto de vista psiquiátrico en fases precedentes. No se trataría de etapas en sentido cronológico o lineal, sino más bien de fases que pueden reconocerse en sus entrelazamientos y en formas de coexistencia que se presentan, en ocasiones, como aparentemente contradictorias entre sí.

\section{La fase pre-medicalizadora de la infancia anómala: la idiocia y el imbécil moral}

Esta primera fase podría ser definida como pre-medicalizadora de los comportamientos disruptivos en la infancia, en la medida que se caracteriza por su estatuto más observacional que intervencionista, referenciado, además, en la neuropsiquiatría de la vida adulta. Esta fase abarcaría un extenso período que se extiende a lo largo del siglo XIX hasta inicios del siglo XX, desarrollada inicialmente en torno a la observación de la 
"locura (del adulto) en el niño" (BERCHERIE, 2001) con el propósito de identificar signos de patologías mentales previamente descritas en adultos, como excitación/manía, depresión /melancolía, histeria, epilepsia, entre otros. La infancia se concibe aquí como algo que muestra al adulto potencial (TELLES, 2006), pero todavía sin que esta percepción alcance una dimensión realmente política como ocurrirá con la fase siguiente en la cual se convertirá en albo privilegiado de estrategias biopolíticas de carácter higienista y eugenésico. Otro elemento importante de la mirada psiquiátrica en esta fase se refiere al despliegue de debates acerca del problema del retardo mental, su etiología e irreversibilidad, que se extendieron a lo largo del siglo XIX, en función de la entidad clínica definida por Esquirol en 1820 como idiocia o idiotismo (TELLES, 2006). Para algunos autores (LOBO, 2008), la problemática de la idiocia fue la que efectivamente dio inicio a la psiquiatrización de la infancia, al inaugurar condiciones inéditas para realizar observaciones que permitieron establecer diferencias entre la infancia normal y la infancia anormal, fundamentalmente a partir de comparaciones entre edad mental y edad cronológica. Ese trabajo de observación del idiotismo posibilitó, también, la colonización del espacio escolar por medio de prácticas psicopedagógicas que progresivamente se extendieron a la población infantil considerada normal.

Sin embargo, los puntos de vista de la psiquiatría que muestran una clara preocupación por la relación entre los trastornos mentales en la infancia y sus conexiones con la peligrosidad social comenzarían a desarrollarse con nitidez durante la segunda fase del proceso medicalizador, localizable en diferentes países a partir de la segunda y tercera décadas del siglo XX.

\section{La biopolitización medicalizadora de la infancia socialmente problemática}

La medicalización propiamente dicha de los comportamientos anormales durante la niñez se habría tornado posible a partir de la valorización biopolítica de la infancia., amparada en criterios higienistas $y$, en algunos períodos y contextos, al mismo tiempo eugenésicos. En esta fase, la psiquiatría experimenta una marcada influencia de los discursos y las prácticas higienistas, suscitando un creciente interés por 
los comportamientos que se manifiestan en la infancia como desviaciones normativas en las áreas de la sexualidad, de la escuela y del conflicto con la ley (COSTA, 1976).

En Brasil, los trabajos realizados por la Liga Brasileira Higiene Mental (LBHM) muestran la existencia de conexiones relevantes entre el conocimiento psiquiátrico de ese período y las estrategias biopolíticas orientadas a la gestión del espacio urbano. Así, por ejemplo, el médico Ernani Lopes propuso como medidas profilácticas para los "menores incorregibles" combatir el alcoholismo y la sífilis de los procreadores, evitar uniones conyugales de personas "pervertidas" y esterilizar a los “degenerados" (LOPES, 1930 apud COSTA, 1976, p. 45).

El higienismo representaba el principal pilar de los procesos de medicalización social desde finales del siglo XIX, y se manifestaba en la tendencia a codificar en términos médico-sanitarios una amplia gama de problemas sociales, especialmente aquellos relativos a la reproducción de la fuerza de trabajo (DONNANGELO, 1979) y a las condiciones de vida de los sectores de población urbana en situación de pobreza. .En este sentido, la higiene puede concebirse como una de las dimensiones más relevantes de las estrategias biopolíticas desplegadas en defensa de la sociedad (ORTEGA; MITJAVILA, 2005). Contribuyó a la difusión de una perspectiva ampliada de los problemas de salud en la población, basada en conocimientos oriundos de áreas como la salud pública, la medicina social, además de la economía, la demografía, la estadística, en fin, apoyándose en conocimientos que permitieron poner en evidencia la naturaleza social y política de los problemas de salud en la población.

Las ideas higienistas no demoraron en extenderse al campo de la salud mental. (COSTA, 1976) En ese contexto, tres elementos se convirtieron en los principales focos de la higiene mental: prevención, eugenesia y control disciplinante de los individuos. La orientación preventiva del higienismo se apoyaba en la necesidad de anticipar los problemas que podrían comprometer, en el futuro, la pureza de la "raza" evitando así su degeneración. El reconocimiento de la importancia biopolíticas de la infancia se encuentra en el corazón de estos procesos. Por lo tanto, la 
infancia comienza a ser problematizada y capturada por la lente de un tipo de conocimiento médico basado en principios higienistas como puede observarse en las preocupaciones condensadas en las figuras del "niño problemático" y del "menor incorregible" descriptas, respectivamente, por los médicos Arthur Ramos (1950) y Ernani Lopes (1930). Desde la perspectiva de esos dos médicos, se trata de desviaciones de la normalidad en los dos sentidos atribuidos a este término por Canguilhem (1986): estadístico (de lo normal como lo más frecuente) y normativo o axiológico (de lo normal como lo deseable), denotando este segundo significado el carácter profundamente moral de la psiquiatría y el papel de los psiquiatras como verdaderos emprendedores morales (BECKER, 1963).

Los menores incorregibles, en su modalidad más severa, se caracterizan por una anormalidad muy pronunciada, con tendencias perversas derivadas de su "inafectividad" congénita. Desde temprana edad muestran una impresionante incapacidad de afecto y completa indiferencia ante los cuidados que reciben de su madre o nodriza. Incapaces de sentir carińo, su placer parece consistir, al contrario, en pegar, estropear, lastimar, hacer el mal [...]. De forma paralela, se observa exaltación precoz (o perversión) de los apetitos, tales como voracidad, deseos sexuales sin moderación, sadismo, tendencia al consumo de alcohol y, además, pereza, agresividad gratuita con el prójimo, autoritarismo, fanfarronería, fabulación, indisciplina. (LOPES, 1930, 243). ${ }^{2}$

La prevención, como mecanismo biopolítico, se convirtió en un motor de los proyectos de la higiene mental. En términos etiológicos, la "psicopatía" era percibida como responsable por una considerable proporción de crímenes. Encontrar en el "menor incorregible" el embrión del psicópata permitiría detectar al delincuente del futuro. Por lo tanto, identificar a este "pre-delincuente" ya en la infancia se convierte, a partir de este período, en una misión que la medicina psiquiátrica asume como propia y la mantiene hasta el presente.

Puede observarse, entonces, la emergencia de un patrón de psiquiatrización de la infancia basado en su valoración como capital biopolítico, en función de su impacto futuro sobre la composición y la

2 Traducción propia del original en portugués. 
calidad de la base poblacional de la sociedad. El significado biopolítico de la infancia se encontraba, así, asociado a discursos y prácticas eugenésicas que, en diversos contextos nacionales, proliferaron en nombre de la pureza racial y del destino de la nación (STEPAN, 2005).

La patologización de los comportamientos disruptivos no alcanza en esta fase solamente a "los menores incorregibles". Así, por ejemplo, la categoría "imbécil moral" aparece en la literatura médica fuertemente asociada al retardo mental de forma tal que resulta difícil diferenciar una categoría de la otra, especialmente en lo que concierne a las conexiones entre debilidad mental y debilidad moral. Ambas corresponderían a deficiencias menos severas que la imbecilidad pero habitualmente asociadas al "vicio" y al crimen como resultado de un mismo tipo basal de déficit: "deficiencia de la voluntad inhibitoria" (STILL, 1902 apud CALIMAN, 2010). Ese tipo de discapacidad, que solía ser etiológicamente atribuida a factores biológicos, constitucionales o hereditarios, establecía las barreras terapéuticas intransponíbles propias de las anomalías por déficits, limitando el proceso de su medicalización al diagnóstico y a las medidas de contención basadas en el confinamiento manicomial o asilar dado su carácter irrecuperable. Sin embargo, la cuestión de la asociación de los déficits inhibitorios de la voluntad con el comportamiento inmoral se convirtió en un residuo histórico que reaparecerá en fases posteriores de los procesos de medicalización de la infancia socialmente problemática, pero bajo nuevos rótulos diagnósticos, como el TDAH y el TOD, razón por la cual este asunto será retomado más adelante.

\section{Preventivismo sanitarista, medicalización del espacio familiar y gestión de la infancia problemática}

El influjo del psicoanálisis y de la psicopatología dinámica sobre el pensamiento médico desempeńó un rol importante en la génesis de esta nueva fase caracterizada por la consolidación de la medicalización de la infancia. La incorporación de esas perspectivas a lo largo del siglo XX creó condiciones de posibilidad para un nuevo tipo de exaltación del papel de la maternidad, de la familia y de los vínculos psicoafectivos en sus efectos sobre condiciones relativas a la salud mental infantil. Se trata 
de una transformación de los objetos de la psiquiatría que se inscribe en una dinámica experimentada de manera más amplia por la sociedad y sus respuestas organizadas a los problemas en el área de la salud.

En ese sentido, podría afirmarse, por lo menos en términos hipotéticos, que las principales instituciones modernas responsables por la prevención y gestión de la infancia socialmente problemática consiguieron mantener bajo estado de relativa latencia la psiquiatrización de algunos tipos de comportamientos disruptivos de niñas/os y adolescentes. En realidad, no se trata de la aparición en escena de nuevas instituciones y sí del desempeño más o menos eficiente de la familia, la escuela y el Estado como principales esferas institucionales de las sociedades modernas.

Así, por ejemplo, el modelo burgués y patriarcal de familia en el cual las sociedades capitalistas se apoyaron alcanzó posiblemente su mayor nivel de institucionalización en este período. De esta forma, la familia pasó a ser crecientemente responsabilizada, no solo por el cumplimiento de las clásicas funciones de reproducción, socialización y protección de su miembros, sino también de prevención, control y gestión de los comportamientos socialmente indeseables de las/os niñas/os. Diversos dispositivos fueron incorporados por las familias para prevenir y gestionar los comportamientos disruptivos, envolviendo desde la educación de adultos para el ejercicio de los roles parentales, pasando por la utilización de castigos físicos y psicológicos hasta la determinación de medidas de institucionalización de los "menores incorregibles" en colegios privados con internado o en instituciones asilares, medidas estas últimas que aún eran consideradas socialmente aceptables durante la mayor parte del siglo XX. Evidentemente, eso no significó que todo tipo de comportamiento socialmente indeseable permaneciese bajo la competencia institucional exclusiva de la familia. Ciertas condiciones, tales como las psicosis y la depresión infantiles, se convirtieron en objetos privilegiados de la psiquiatría en esta fase de los procesos medicalizadores de la infancia, por medio de un repertorio ecléctico de recursos diagnósticos y terapéuticos (BERCHERIE, 2001; CALIMAN, 2010).

Corresponde igualmente destacar que se trata de un período en el cual se observa una progresiva pérdida de vigencia del higienismo y de la 
vieja salud pública, y su sustitución por los principios del preventivismo sanitarista (ORTEGA; MITJAVILA, 2005). Este se encuentra asociado a la emergencia de estrategias biopolíticas que responden a un nuevo tipo de racionalidad que comienza a tornarse dominante en las sociedades tardomodernas y que deviene, de acuerdo con la perspectiva de diversos autores, de la radicalización de algunos de los cimientos sobre los cuales se erigió el propio proyecto de modernidad tales como la confianza institucional en la ciencia y la tecnología, el capitalismo como modo de producción, la orientación hacia el futuro y el riesgo como dispositivo de regulación social, por citar algunos de los más importantes (GIDDENS, 1991).

Ese nuevo tipo de racionalidad comienza a manifestarse en el campo del saber médico-sanitario. En ese sentido, se destaca la progresiva endogenización de los modelos etiológicos utilizados para explicar e intervenir en los problemas de salud tanto a nivel individual como colectivo. En el marco de esta nueva lógica, las estrategias interpretativas fundacionales del campo de la salud colectiva, que propugnaban el reconocimiento de la salud como un problema eminentemente social y político de dimensiones macroscópicas, comienzan a perder espacio frente a diversos modelos que le atribuyen un papel etiológico relevante al ambiente familiar y a la responsabilidad individual en la producción de la salud y la enfermedad (ORTEGA; MITJAVILA, 2005; MITJAVILA, 2015), característica que, como será profundizado más adelante, se presentará de forma más estructurada y con mayor alcance sistémico en los procesos de medicalización que se observan durante el pasaje del siglo $\mathrm{XX}$ al siglo XXI.

De acuerdo al análisis realizado por Ayres (1995, p. 261), el preventivismo se caracteriza por el "[...] predominio de lo individual sobre lo colectivo, de lo técnico sobre lo político, de lo material sobre lo social, de lo médico asistencial sobre lo médico sanitario, de lo privado sobre lo público". En tal sentido, el preventivismo puede ser definido como

[...] la doctrina médica que, precisamente, retraduce la concepción ampliada de determinación del proceso salud enfermedad, tal como fue desarrollada por las disciplinas ligadas al campo de la higiene y de la salud pública desde el siglo XIX, en prácticas de carácter eminentemente técnico, esencialmente dirigidas al ámbito de los cuidados 
individuales y básicamente orientadas al desarrollo de acciones asistenciales y educativas simplificadas, con baja densidad de tecnología especializada y equipamientos materiales y dirigidas a minimizar los padecimientos y los costos de la asistencia especializada. (ORTEGA; MITJAVILA, 2005, p. 215).

El preventivismo sanitarista instituyó en esta fase un conjunto de mandatos destinados a consagrar la centralidad de los roles del individuo y de la familia en el cuidado de la salud. Esto también parece verificarse en el caso de la medicalización de los comportamientos disruptivos en la infancia. En ese sentido, se observa en los manuales de psiquiatría de este período una creciente presencia de estrategias discursivas que le atribuyen a la familia un carácter patogénico, y hasta criminógeno, toda vez que se desvíe de la estructura y funcionamiento prescritos por el modelo de familia utilizado como parámetro de normalidad. Los siguientes fragmentos extraídos de un manual de psiquiatría ilustran esa centralidad atribuida a la familia como factor etiológico de la anormalidad:

[...] la violencia humana es una consecuencia de la perversión de los valores dominantes y del desarrollo psicológico provocado por graves perturbaciones en la interacción Madre-Hijo-Padre. (CORDEIRO, 2003, p. 49). ${ }^{3}$

El carácter cálido o indiferente de estas respuestas parentales proyectadas sobre el nińo es fuertemente determinante de normalidad o de patología del desarrollo de la autoestima [...]. Es en este permanente juego de transferencias que el niño desarrolla su capacidad de regular internamente la autoestima y que, progresivamente, representaciones mentales de sí y de los otros (Self y Objeto) se delimitan a través de la separación y de la individuación. (CORDEIRO, 2003, p. 27). ${ }^{4}$

Específicamente en lo que concierne a la interpretación etiológica del trastorno de personalidad antisocial (TPA) en la vida adulta, la familia suele aparecer como uno de los principales agentes patógenos. Así, por ejemplo, entre los indicadores de peligrosidad criminal formulados por Maranhão ${ }^{5}$, Araújo e Menezes (2003) destacan el carácter criminógeno de la familia cuando el ejercicio de los roles de sus miembros se desvía de los mandatos

\footnotetext{
3 Traducción propia del original en portugués.

4 Traducción propia del original en portugués.

5 Odon Ramos Maranhão (1924-1995) fue Profesor Titular de la Facultad de Derecho de la Universidad de São Paulo y Profesor de Criminología en el curso de posgrado de esa misma Facultad.
} 
institucionales, generando condiciones negativas para lograr una socialización bien sucedida de las/os hijas/os en términos de adaptación social.

La familia es, sin lugar a dudas, un factor importante de la formación de la personalidad. El hogar solo da cuenta de las necesidades (de sus miembros) si cumple con sus funciones básicas. Si la madre, que representa la fuente de afecto, no comprende ni acepta al hijo; si el padre, en cuanto contacto con la realidad, es irascible y violento, omiso o irresponsable; si la relación con los hermanos es excesivamente belicosa, el hijo no desarrollará adecuadamente el sentimiento de fraternidad tan imprescindible en los procesos adaptativos y, algo no tan raro, procurará afecto en la calle, donde encontrará a otros en situación análoga, pasando a adoptar otros códigos de conducta y, para sobrevivir, recurrirá a las acciones antisociales, restando la readaptación como algo difícil y arduo. (ARAúJO; MENEZES, 2003, p. 240).

La intromisión del saber y de la práctica médica en la vida familiar no constituye por cierto una novedad histórica. La higienización y la ortopedia moral de las familias en situación de pobreza ya se habían firmemente instalado en el siglo XIX de forma bastante generalizada en las sociedades occidentales. Por ejemplo, la salud reproductiva de las mujeres y la salud de las/os nińas/os se convirtieron tempranamente en objetos de valor estratégico para los procesos medicalizadores, tanto para el propio saber médico como, en un sentido más amplio, para la construcción del orden institucional de la modernidad, aspectos detalladamente examinados por la literatura disponible (BOLTANSKI, 1974; DONZELOT, 1986; FOUCAULT, 1992; BARRÁN, 1995). Sin embargo, la colonización médica del espacio familiar se ha deparado, desde sus orígenes hasta el presente, con diversos obstáculos socioculturales que en alguna medida opacaron parte de sus resultados como lo han puesto en evidencia trabajos sobre tópicos tales como la medicalización de la maternidad y las pautas de socialización de las/os nińas/os en el ámbito familiar (BOLTANSKI, 1974; MITJAVILA; ECHEVESTE, 1994).

En lo que se refiere a la medicalización específicamente de las pautas familiares de gestión del comportamiento infantil disruptivo, no parecen abundar resultados de trabajos provenientes de las ciencias sociales. Sin embargo, sí se cuenta con resultados de investigaciones que analizan la emergencia y los modos de funcionamiento de estrategias biopolíticas que organizan la gestión neoliberal de los riesgos en las sociedades tardomodernas. (MITJAVILA; VECINDAY, 2011). En este contexto, comienza a instalarse un nuevo tipo de racionalidad a cuyos principios posiblemente responda lo que puede considerarse como la cuarta e históricamente más 
reciente fase de problematización y medicalización de los comportamientos disruptivos en la infancia.

\section{La lógica del riesgo y la medicalización de la infancia considerada socialmente problemática}

Lo que aquí se delinea como la cuarta fase de la medicalización de la infancia socialmente problemática se caracteriza por la formulación relativamente reciente de dos nuevas categorías diagnósticas bajo las cuales se codifica psiquiátricamente un conjunto polimorfo de signos y síntomas que, en su mayor parte, son definidos por su carácter socialmente disruptivo. Se trata de los ya mencionados TDAH y TOD. Escaparía a los fines del presente ensayo realizar una presentación detallada de ambos trastornos, tarea ya ejecutada de forma exhaustiva por una parte significativa de la literatura sobre el tema. Lo que sí se pretende es identificar los tipos de atributos y comportamientos que esos diagnósticos problematizan bien como las formas de enunciación de la anormalidad y de la peligrosidad que dichos instrumentos transportan.

Los principales atributos básicos que componen el diagnóstico de $\mathrm{TDH}$, detectables a partir de la primera infancia, son impulsividad, hiperactividad y desatención. Tanto en la cuarta como en la quinta y última edición del Manual de Estadística y Diagnóstico de la Asociación Americana de Psiquiatría (APA, 2013), se describe este trastorno en su asociación con una reducción del desempeño escolar y del éxito académico así como con el rechazo social. También se señala que niños diagnosticados con TDH: [...] tienen una probabilidad significativamente mayor que sus pares de desarrollar trastorno de conducta en la adolescencia y trastorno de personalidad antisocial en la vida adulta, aumentando, así, la probabilidad de trastornos por uso de substancias y prisión" (APA, 2013, p. 63).

Por su parte, TOD (identificado por el código 313.81 en DSM-5 y F91.3 en la CID-9) consiste en una entidad mórbida que pertenece al grupo de los llamados "trastornos disruptivos del control de impulsos y de la conducta” (CAPONI, 2018). Es una categoría diagnóstica que permite registrar, a partir de la indagación temprana de la trayectoria biográfica, la presencia de varias facetas de la malignidad y peligrosidad social de algunos 
niños, evidenciadas por la observación de signos y síntomas clasificados en tres dimensiones: (i) estado de ánimo enojado/irritable, (ii) cuestionador/ desafiante y (iii) naturaleza vengativa. El manual incluye una advertencia sobre la importancia de tener en cuenta el sufrimiento que estas conductas producirían "para los otros en su contexto social inmediato (familia, compañeros, escuela, colegas)” (APA, 2013, p. 463).

La definición de factores de riesgo para el TOD guarda un alto grado de correspondencia con las interpretaciones etiológicas del "trastorno de personalidad antisocial” (TPA) en la vida adulta (MITJAVILA; MATHES, 2012). En ambos casos, se enumeran factores etiológicos de dos tipos: biológicos y sociales. Los factores sociales (que el DSM-5 define como "ambientales") comprenden, entre otras, las siguientes variables: "bajo nivel socioeconómico", "historia parental de psicopatología", "crimen parental", además de diversas formas de déficit parental en materia de cuidado, afecto y disciplina. Estos son criterios diagnósticos que apuntan a trayectorias biográficas caracterizadas por la peligrosidad criminal y social en general, a partir de una perspectiva que sugiere la presencia de una mirada médica aparentemente criminalizadora de la pobreza.

Esas dos categorías diagnósticas condensan de manera ejemplar el campo semántico y las formas de enunciación de los discursos de la psiquiatría contemporánea sobre los comportamientos disruptivos en la infancia. Se trata de un tipo de saber que, en términos de contenido, estaría reactualizando la interpretación de patologías como resultado de déficits en materia de autocontrol de los impulsos. En ese sentido, el TDAH se refiere a un disturbio caracterizado por déficits volitivos y morales que también estaban presentes en las descripciones psiquiátricas de la idiocia y de la imbecilidad moral. Como ya observara Caliman (2010), lo novedoso ahora se refiere más a la etiología que a los propios déficits. Si bien actualmente se observa cierta continuidad en la atribución de los déficits de la inhibición a determinantes biológicos, éstos ya no remiten a lo hereditario o a lo constitucional, pasándose a explicar su producción como resultado de factores neuroquímicos del funcionamiento cerebral (CALIMAN, 2010).

En lo que se refiere a los aspectos enunciativos de esta discursividad del saber psiquiátrico acerca de la infancia socialmente problemática, se 
observa la presencia de un tipo de racionalidad que representaría una ruptura con fases precedentes de los procesos medicalizadores en esta área. Se trata de un tipo de racionalidad que se apoya en la incorporación del riesgo como lenguaje y como dispositivo biopolítico.

Una de las principales funciones estratégicas del riesgo como dispositivo es proporcionar un instrumento para la administración de la incertidumbre y el miedo, especialmente en relación con la ocurrencia de eventos futuros de carácter indeseable. En este sentido, el cálculo y la evaluación de riesgos en diferentes áreas de la vida social suelen informar menos sobre la existencia real de peligros o amenazas que sobre las racionalidades, intereses y pautas culturales que organizan la percepción y codificación de esas amenazas (DOUGLAS; WILDAVSKY, 1982; GIDDENS, 1991). Por lo tanto, como señala Beck (1997), el lenguaje del riesgo proporciona un instrumento para calcular lo que a menudo, de hecho, es incalculable, a través de una sintaxis relativamente uniforme que, en virtud de su aparente neutralidad y cientificidad, se muestra versátil para transportar una enorme diversidad de significados.

Los comportamientos infantiles disruptivos siempre han generado fuertes dosis de incertidumbre y de preocupación en las sociedades modernas, las cuales han desplegado diferentes mecanismos institucionales para prevenirlos y administrarlos. En ese sentido, la familia, la religión, la escuela y el propio saber médico han históricamente operado como recursos institucionales relevantes tanto en el área de la prevención como de la gestión de la infancia socialmente problemática. Por razones cuyo abordaje excede los límites del presente trabajo, la medicalización de los comportamientos disruptivos en la infancia parece haberse incrementado notoriamente en períodos muy recientes como resultado, quizás, de un proceso de reorganización de la división del trabajo institucional dirigido a la gestión de la infancia en las sociedades tardomodernas. Apenas con la finalidad de ilustrar las posibles consecuencias que este nuevo tipo de racionalidad podría tener, se puede mencionar la nueva división del trabajo entre diferentes instituciones y agentes que promueve el proceso de realización de cada diagnóstico de TDAH. Fuertemente estructurado por medio de la aplicación de cuestionarios respondidos por los miembros de la familia y de la escuela, el diagnóstico suele ser realizado por médico psiquiatra o neuropediatra a partir, aunque no exclusivamente, 
de observaciones de segundo grado del comportamiento de la niña o niño, esto es, a partir del análisis que el médico realiza de las observaciones de los observadores de la persona cuyo comportamiento es el objeto de la evaluación (RAFALOVICH, 2002).

\section{Para concluir}

El análisis preliminar de las trayectorias experimentadas por la medicalización do comportamiento infantil disruptivo permitió identificar cuatro fases diferenciadas entre sí en función de los tipos de objetos y de los modelos etiológicos que la psiquiatría privilegió en cada una de ellas.

En ese sentido, el saber psiquiátrico experimentó un conjunto de transformaciones que van desde el énfasis inicial de la psiquiatría en problematizar las anomalías de la insuficiencia (cognitivas o morales) consideradas bastante irreversibles para centrarse, en períodos más recientes, también en formas de comportamiento disruptivo, pero consideradas potencialmente manejables, bajo rótulos diagnósticos tales como el TDAH y el TOD.Provisoriamente, podemos registrar dos clases de observaciones sobre ese aspecto.

a) Por un lado, las anomalías relacionadas con los déficits cognitivos comienzan progresivamente a perder espacio en el discurso de la clínica psiquiátrica infantil junto con la pérdida de vigencia de los ideales eugenésicos que se situaban en el ámbito del problema de la degeneración de la "raza".

b) Por otro lado, a lo largo del siglo XX, se observa una progresiva descomposición conceptual de la noción de "menor incorregible", no solo como resultado de los avances en materia de psicología evolutiva y de los estudios psicopatológicos, sino también por la percepción de su carácter absoluto e irreversible y, por lo tanto, difícilmente psiquiatrizable.

El TDAH codifica un conjunto de atributos y comportamientos que, desde la primera infancia, resultan ser socialmente problemáticos, ya que están vinculados etiológicamente a insuficiencias de los niños para cumplir con mandatos y expectativas sociales en los ambientes escolar, familiar y social en general. Se trata de una codificación psiquiátrica de lo 
que socialmente pueden definirse como desvíos comportamentales cuya administración es resistente a los mecanismos de control social por parte de las instituciones sociales (familia, escuela) responsables por la socialización primaria de las niñas y de los niños.

Sería posible asociar estas inflexiones en la psiquiatrización de la infancia con la emergencia, hacia fines del siglo XX, de un nuevo tipo de racionalidad dirigida a la administración política de la vida, caracterizada, entre otras cosas, por un nuevo tipo de funcionamiento del biopoder, con una renovación de sus objetos y, fundamentalmente, de los mecanismos y tecnologías en los cuales se apoya. En este nuevo contexto, se puede plantear la hipótesis de que las nuevas categorías nosológicas en las que se materializan las miradas de la psiquiatría contemporánea sobre la infancia socialmente problemática estarían revelando una redefinición del papel biopolítico de la infancia. Bajo estas condiciones, la infancia comenzaría a perder fuerza en su consideración como capital humano para el futuro de la población (aunque este elemento todavía aparezca retóricamente como un referente discursivo) pasando a adquirir un nuevo estatuto por su fuerza disruptiva a nivel familiar, educativo y comunitario. Los niños diagnosticados con TDAH y TOD representarían un tipo de riesgo social que afectaría, antes o más que a la composición de la población adulta del futuro, a la calidad actual de la población adulta de sus propias familias porque secuestran tiempo y energía que esa población debería destinar al desempeño de funciones no parentales (como trabajadores y como consumidores). La industria farmacéutica viene, en ese sentido, proporcionando los medios para que los adultos, con sus hijos medicados, no vean ofuscados el desempeño de roles en los mercados de trabajo y de consumo

Lo anterior evidenciaría la actual fragilidad relativa de la familia y de la escuela como instituciones de control social, ya que los comportamientos disruptivos en la infancia estarían escapando a los mecanismos de regulación social propios del ejercicio del poder y de la autoridad en estos espacios. La medicalización de objetos sociales, como han señalado varios autores, deriva, en muchas ocasiones, de la transferencia para el campo de la medicina de competencias previamente ubicadas en ciertas áreas institucionales (religión, familia), y de alguna manera esto sería lo que ha 
estado ocurriendo progresivamente con la llamada infancia socialmente problemática (CRAWFORD, 1980).

Finalmente debe destacarse un tercer elemento que revelan estas nuevas categorías diagnósticas y que es algo que ha sido ampliamente discutido en la literatura sobre el tema: su apertura a la colonización médica. En el pasado, las nociones de idiotez y de "menor incorregible" denotaban condiciones anómalas que, por no constituir enfermedades, oponían resistencia a su patologización. Pero la relativamente reciente introducción de la idea de trastorno (en oposición a la noción de enfermedad) ha generado nuevas e infinitas posibilidades para patologizar y, en consecuencia, psiquiatrizar atributos y comportamientos socialmente perturbadores en nombre de la prevención de riesgos y de la salud mental (MITJAVILA; MATHES, 2012).

\section{Referencias}

AMERICAN PSYCHIATRIC ASSOCIATION (APA). Diagnostic and statistical manual of mental disorders: DSM-IV-TR. 4. ed. Arlington: APA, 1994.

AMERICAN PSYCHIATRIC ASSOCIATION (APA).Diagnostic and statistical manual of mental disorders: DSM-V. 5. ed. Arlington: APA, 2013.

ARAÚJO, C. T. L.; MENEZES, M. A Execução penal, exame criminológico e apreciação dos indicadores de potencial criminógeno. In: RIGONATTI, P. S.; SERAFIN, A. P.; BARROS, E. L. de. Temas em psiquiatria forense e psicologia jurídica. São Paulo: Vetor, 2003. p. 229-245.

AYRES, J.R.C.M. Açáo Comunicativa e conhecimento científico em epidemiologia: origens e significados do conceito de risco, (Tese de Doutorado) São Paulo, Faculdade de Medicina da Universidade de São Paulo (USP), 1995.

BARRÁN, J. P. Medicina y Sociedad en el Uruguay del Novecientos. El poder de curar. Tomo 1. Montevideo: Ediciones de la Banda Oriental, 1995.

BECK, U. La reinvención de la política: hacia una teoría de la modernización reflexiva. In: BECK, U.; LASH, S.; GIDDENS, A. Modernización reflexiva: política, tradición y estética en el orden social moderno. Madrid: Alianza, 1997. p. 16-73.

BECKER, H. Los extrańos: sociología de la desviación. Buenos Aires: Tiempo Contemporáneo, 1971.

BERCHERIE, P. A clínica psiquiátrica da criança. In: CIRINO, O. Psicanálise e psiquiatria com crianças: desenvolvimento ou estrutura. Belo Horizonte: Autêntica, 2001. p.129-144.

BOLTANSKI, L. Puericultura y moral de clase. Barcelona: Laia, 1974.

CALIMAN, L. V. Notas sobre a história oficial do transtorno do déficit de atenção/hiperatividade 
TDAH. Psicol. cienc. prof., Brasilia, v. 30, n. 1, 2010. Disponible en: http://www.scielo.br/scielo. php?script=sci_arttext\&pid=S1414-98932010000100005\&lng=en\&nrm=iso. Acceso en:24 jun. 2020 .

CANGUILHEM, G. Lo normal y lo patológico. México: Siglo XXI, 1986.

CAPONI, S. N. Dispositivos de segurança, psiquiatria e prevenção da criminalidade: o TOD e a noção de criança perigosa. Saude soc., São Paulo, v. 27, n. 2, jun. 2018. Disponible en: http:// www.scielo.br/scielo.php?script=sci_arttext\&pid=S0104-12902018000200298\&lng=en\&nrm =i so. Acceso en: $1^{\circ}$ de jul. 2020.

CORDEIRO, J. C. D. Manual de Psiquiatria Clínica. Lisboa: Fundação de Calculstre Gulbenkian, 2003.

COSTA, J. F. História da Psiquiatria no Brasil. Rio de Janeiro: Editora Documentário, 1976.

CRAWFORD, R. Healthism and the medicalization of everyday life. International Journal of Health Services, v. 10, n. 3, p. 365-388, 1980.

Donnangelo, C. Saúde e sociedade. São Paulo, Duas Cidades, 1979.

DONZELOT, J A policia das famílias. Rio de Janeiro: Ed. Graal. 1986.

DOUGLAS, M.; WILDAVSKY, A. Risk and culture. Oxford: Basil Blakwell, 1982.

FOUCAULT, 1992. Poder-corpo. In: Machado, Roberto (org.). Microfísica do poder. Rio de Janeiro, Graal, 1992.

GIDDENS, A. As conseqüências da modernidade. São Paulo: Editora Universidade Estadual Paulista, 1991.

LOBO, L. F. Os infames da história: pobres, escravos e deficientes no Brasil. Rio de Janeiro: Lamparina. 2008.

MITJAVILA, M. R.; ECHEVESTE, L. Sobre a construção social do discurso médico em torno da maternidade. In: COSTA, A. O.; AMADO, T. (org.). Alternativas Escassas. Saúde, Sexualidade e Reprodução na América Latina. São Paulo: Fundação Carlos Chagas; Editora 34, 1994. p. 283-300.

MITJAVILA, M. R.; VECINDAY, L. El enfoque de riesgo como dispositivo individualizador en el campo social. In: LORENTE, B.(org.). Transformaciones del Estado Social. Perspectivas sobre la Intervención social en Iberoamérica. V. 1. 1. ed. Buenos Aires: Miño y Dávila, 2011. p. 79-104.

MITJAVILA, M. R.; MATHES, P. G A psiquiatria e a medicalização dos anormais: o papel da noção de transtorno de personalidade antissocial. INTERthesis, Florianópolis, v. 9, p. 84-100, 2012 .

MITJAVILA, M. Medicalização, risco e controle social. Tempo soc., São Paulo, v. 27, n. 1, jun. 2015. Disponible en: http://www.scielo.br/scielo.php?script=sci_arttext\&pid=S010320702015000100117\&lng=en\&nrm=iso. Acceso en: 1jul. 2020.

ORTEGA, E.; MITJAVILA, M. R. O preventivismo sanitarista e a institucionalização do Serviço Social no Uruguai neobatllista: uma indagação genealógica. Revista Katálysis, Florianópolis, 
v. 8, n. 2, jan. 2005. Disponible en: https://periodicos.ufsc.br/index.php/katalysis/article/ view/6112. Acceso en: $1^{\circ}$ jul. 2020.

RAFALOVICH, A. Framing the ADHD child: History, discourse and everyday experience. 2002. 417 f. (Tesis de Doctorado) Department of Anthopology and Sociology, University of British Columbia, Vancouver, 2002.

RAMOS, A. A criança problema: a higiene mental na escola primária. 3. ed. Rio de Janeiro: Casa do Estudante, 1950.

STEPAN, N. A Hora da Eugenia: raça, gênero e nação na América Latina. Rio de Janeiro: Editora Fiocruz, 2005.

STILL, G. Some abnormal psychical conditions in children - Lecture I. The Lancet, p. 1008-1012, 1902.

TELLES, H. P. R. S. Infância e saúde mental: teoria, clínica e recomendaçóes para políticas públicas. 2006. Dissertação (Mestrado em Saúde Materno Infantil) - Faculdade de Saúde Pública, Universidade de São Paulo, Sáo Paulo, 2006.

Recebido: 30/06/2020

Aceito: 31/08/2020 


\section{On the medicalization of socially problematic childhood: objects and trajectories of psychiatry}

\section{Abstract}

The article examines the medicalization processes of disruptive behaviors in childhood from the point of view of their codification by psychiatric knowledge. Four phases of the medicalizing processes of childhood considered socially problematic and their articulations with biopolitical strategies for managing the abnormality are presented.

Keywords: Medicalization. Biopolitics. Disruptive child behavior. Psychiatry. 